\title{
The Prospective Two-Dimensional Graphene Nanosheets: Preparation, Functionalization, and Applications
}

Zhi Yang*, Rungang Gao, Nantao Hu, Jing Chai, Yingwu Cheng, Liying Zhang, Hao Wei, Eric Siu-Wai Kong, Yafei Zhang*

(Recevied 10 December 2011; accepted 20 December 2011; published online 10 January 2012.)

\begin{abstract}
Graphene, as an intermediate phase between fullerene and carbon nanotube, has aroused much interests among the scientific community due to its outstanding electronic, mechanical, and thermal properties. With excellent electrical conductivity of $6000 \mathrm{~S} / \mathrm{cm}$, which is independent on chirality, graphene is a promising material for high-performance nanoelectronics, transparent conductor, as well as polymer composites. On account of its Young's Modulus of $1 \mathrm{TPa}$ and ultimate strength of $130 \mathrm{GPa}$, isolated graphene sheet is considered to be among the strongest materials ever measured. Comparable with the single-walled carbon nanotube bundle, graphene has a thermal conductivity of $5000 \mathrm{~W} /(\mathrm{m} \cdot \mathrm{K})$, which suggests a potential application of graphene in polymer matrix for improving thermal properties of the graphene/polymer composite. Furthermore, graphene exhibits a very high surface area, up to a value of $2630 \mathrm{~m}^{2} / \mathrm{g}$. All of these outstanding properties suggest a wide application for this nanometer-thick, two-dimensional carbon material. This review article presents an overview of the significant advancement in graphene research: preparation, functionalization as well as the properties of graphene will be discussed. In addition, the feasibility and potential applications of graphene in areas, such as sensors, nanoelectronics and nanocomposites materials, will also be reviewed.
\end{abstract}

Keywords: Graphene; Graphite oxide; Functionalization; Sensors; Transparent conductive films; Nanocomposites

Citation: Zhi Yang, Rungang Gao, Nantao Hu, Jing Chai, Yingwu Cheng, Liying Zhang, Hao Wei, Eric Siu-Wai Kong and Yafei Zhang, "The Prospective Two-Dimensional Graphene Nanosheets: Preparation, Functionalization, and Applications", Nano-Micro Lett. 4 (1), 1-9 (2012). http://dx.doi.org/10.3786/nml.v4i1. $\mathrm{p} 1-9$

\section{Introduction}

Graphene, a nanometer-thick two-dimensional ana$\log$ of fullerenes and carbon nanotubes, comprises a two dimensional layer of $\mathrm{sp}^{2}$-hybridized carbon atoms, arranged in a hexagonal lattice. Due to its exceptionally outstanding electronic, mechanical, and thermal properties, graphene has aroused much interests among the scientific as well as technology community [1]. More and more publications have emerged focusing on this nanomaterial since 2004 (Fig. 1), not only in the syn- thesis/production of graphene, but also in its implementation in sensors, field emitters, nanoelectronics, nanocomposite materials, and so on. Therefore, it becomes timely to review and summarize the synthesis and processing of graphene for functional nanostructures and devices [2-9].

In this review, we will discuss the progress of the research on the synthesis of the graphene from the materials chemistry and physics standpoint. An overview of the preparation and properties of graphene will also be discussed. In addition, the feasibility and poten-

Key Laboratory for Thin Film and Microfabrication of the Ministry of Education, Research Institute of Micro/Nano Science and Technology, Shanghai Jiao Tong University, Shanghai 200240, P. R. China

*Corresponding author. E-mail: zhiyang@sjtu.edu.cn, yfzhang@sjtu.edu.cn 
tial applications such as sensors, nanoelectronics, and nanocomposite materials will be reviewed as well.

\section{Preparation of graphene}

Majority of the studies on graphene have been focused on the synthesis of single-layer or few-layer graphene. Table 1 summarizes the main methods used for production of graphene, covering the merits as well as the shortcomings of each method.

From highly ordered pyrolytic graphite (HOPG) to the final products, Geim and his colleagues rubbed lithographically patterned pillars and used Scotch tape to perform the thinning of the graphite stuck to the $\mathrm{SiO}_{2} / \mathrm{Si}$ sheets [10]. This mechanical exfoliation method is very easy, and the graphite materials can be readily obtained. Furthermore, single graphene sheet with high quality, applicable in the fabrication of electronic devices, can be easily prepared. However, the device fabricated by this method is very complex, and the reproducibility cannot be assured. Despite of this drawback, many unexpected electronic properties of the graphene sheet can be explored by this method.

Table 1 Main methods for the production of graphene

\begin{tabular}{|c|c|c|c|}
\hline Method & Mechanical exfoliation & Epitaxial growth & graphite oxide-reduced \\
\hline Merits & $\begin{array}{l}\text { Low cost, easy way without any } \\
\text { special equipment }\end{array}$ & $\begin{array}{l}\text { Large area of even film can be ob- } \\
\text { tained, amiable for microelectronic } \\
\text { application }\end{array}$ & $\begin{array}{l}\text { Suitable for large scale production; } \\
\text { Easy control in the solvent for ap- } \\
\text { plication in various fields. }\end{array}$ \\
\hline Disadvantages & $\begin{array}{l}\text { Only for laboratory research Very } \\
\text { hard to control (hard to obtain uni- } \\
\text { form film) }\end{array}$ & $\begin{array}{l}\text { High-temperature operation re- } \\
\text { quired }\end{array}$ & $\begin{array}{l}\text { The lateral size is limited; The re- } \\
\text { duction is usually partial. }\end{array}$ \\
\hline
\end{tabular}

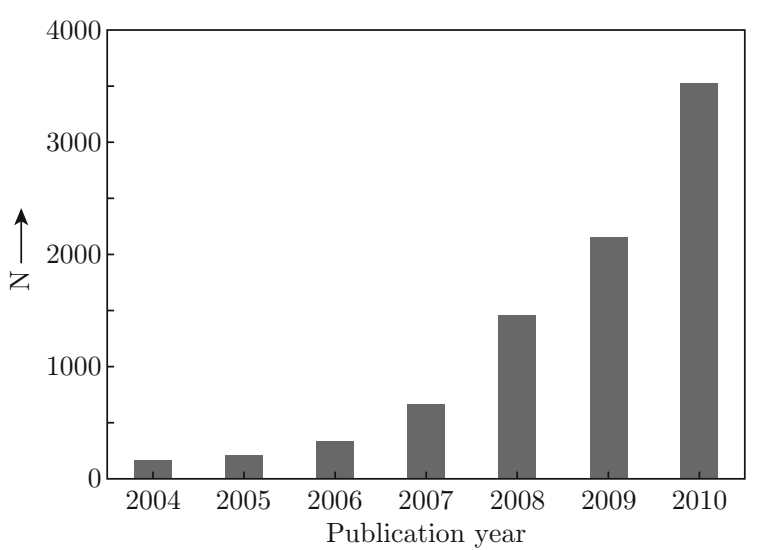

Fig. 1 The increase in the number of publications related to graphene since 2004 (based on the Web of Science database).

As micromechanical cleavage of HOPG was first employed to obtain single-layer graphene [10], various methods of graphene synthesis have been reported, including epitaxial growth on an insulator surface such as $\mathrm{SiC}$ [11] and chemical vapor deposition (CVD) on surfaces of transition metals such as $\mathrm{Ni}$ and $\mathrm{Cu}[12,13]$. Comparing with the mechanical exfoliation method, this method is very suitable for the industrial production of single-layer graphene with large areas, which have great potential application as sensors and transparent conductive films. Although great progress has been achieved by this method, there are still many challenges for us to face, such as the choice of the substrate, how to lower the operation temperature, and so forth.

Chemical reduced graphene (CGR) has aroused much interests due to its relatively easy large-scale production [14]. Through reduction of graphite oxide (GO) suspended in water [15] or organic solvents [16,17], CGR can be easily obtained. Usually, there are three main routes to form GO: Brodie's method [18], Staudenmaier's method [19] and Hummers' method [20]. Hummers' method is commonly exploited today, and many modified Hummers' methods have been reported, optimizing the GO production process. The recent review by Dreyer is an excellent, succinct source of further information on preparation, structure, and reactivity of GO [21]. Many kinds of reducing agents, such as hydrazine [22], $\mathrm{NaBH}_{4}$ [23], ethylenediamine [24], Al powder [25], ascorbic acid [26], and p-phenylene diamine [27] have been used to reduce GO and disperse the resultant CGR in the solvent, which is beneficial for further nanocomposite preparation and device fabrication. UV irradiation method [28] has also been reported to reduce $\mathrm{GO}$ in aqueous dispersion. $\mathrm{TiO}_{2}$ nanoparticles play an important role in the reduction process. Guo et al. [29] has reported that electrochemical reduction could work very well for the reduction of GO, which is a green approach to obtain CGR in aqueous dispersion. Recently, Li et al. [30] reported a dry microwave synthesis method to obtain CGR, which can be considered to be the most efficient route to date in preparing CGR in the large scale.

\section{Functionalization of graphene}

Pristine graphene exhibits poor solubility in both water and organic solvents. Therefore, it is necessary to modify this nanomaterial with functional groups, in order to enhance its dispersity in various solvents.

\section{Covalent functionalization}

Since solution-based chemical reductio n of graphite 
oxide to graphene is a very easy method for large scale production of graphene, it is a great challenge for this method to be adopted for individual graphene sheets having high dispersity in different solvents in a bulk quantity. Since GO possesses several functionalities such as hydroxyl, carboxyl, and carbonyl, it is rather straight forward to be transformed to other functional groups through acylation or esterification $[21,31]$. Through chemical reduction of GO by reducing reagents or thermal treatment, the covalently functionalized graphene can be formed, resulting in a much better dispersity in water or organic solvents. In order to enhance the hydrophilicity or lipophilicity of graphene, some small molecules and polymers, can be introduced to the plane of graphene, through radical addition reaction [32], cycloaddition reaction [33], or diazonium salts reaction [34] during the in situ reduction of GO into graphene. As a result, this would lead to a much better dispersity of graphene in water or organic solvents. Molecules, with special functional applications, can also be attached onto the surface of graphene, resulting in new properties for the functionalized materials. For example, porphyrin (5-4 (aminophenyl)-10, 15, 20-triphenyl porphyrin) is bonded onto graphene oxide by an amino bond. This new functionalized graphene has better optical limiting properties than $\mathrm{C}_{60}$, which could be used in the field of optical switching and other areas [35]. Graphene nanoribbons are successfully functionalized by aryl diazonium salts, with concentration of the functionalized graphene in $\mathrm{N}$ methyl-2-pyrrolidone and N,N-dimethylformamide up to $1 \mathrm{mg} / \mathrm{mL}$. Thickness of graphene nanoribbons are increased due to the covalent attachment between the functional groups and graphene. Therefore, graphene films, nanotubes and other nanomaterials may be functionalized by this method in the future [36]. Graphene, functionalized by model glucose oxidase and immobilized on the polypyrrole-modified electrode surface, exhibits a high sensitivity $(3 \mu \mathrm{M})$, as well as a stable and steady response. It is utilized for glucose detection and could be applied in the field of electroanalytical chemistry. It is also used in the measurement of the plasma glucose level for diabetes diagnosis [37].

\section{Noncovalent functionalization}

The noncovalent functionalization of graphene is achieved by van der Waals forces or $\pi$ - $\pi$ stacking. Noncovalent functionalization generally has little effect on the original properties of the graphene. Natural polymers (lignin and cellulose derivatives) are adsorbed on the graphene surface by hydrophobic interaction and $\pi$ $\pi$ stacking. Indeed, functionalized graphene can be kept in stable condition at high concentration $(0.6-2 \mathrm{mg} / \mathrm{mL})$ in water [38]. Sulfonated polyaniline (Fig. 2(a)) has good stability, electrochemical properties and water solubility, and is therefore used for the non-covalent func- tionalization of graphene sheets. This new functionalized graphene is soluble in water at high concentrations (> $1 \mathrm{mg} / \mathrm{L})$ and exhibits good conductivity, with potential application in the field of electrochemistry [39]. Graphene oxide has been functionalized with endfunctional polymers which includes polystyrene $\left(-\mathrm{NH}_{2}\right)$, polystyrene $(-\mathrm{COOH})$ and poly (methyl methacrylate) $(-\mathrm{OH})$. The successive reduction makes sure that the electrical structure of the $\mathrm{C}$ atom on the graphene plane does not change, and the new functionalized graphene is soluble in solvents such as $\mathrm{N}$-methyl-2-pyrrolidone, $\mathrm{N}$, N-dimethylformamide, ethanol, and methanol for duration of up to one month [40]. Graphene can be functionalized by a small molecule of methylene green (Fig. 2(b)), with good dispersity in the water. The functionalized graphene is well dispersed on the electrode surface and be readily accessible by redox probes and ions. In addition, this functionalized graphene has high electrochemical and electrocatalytic activity towards nicotinamide adenine dinucleotide [41]. Graphene functionalized with tetrapotassium salt of coronene tetracarboxylic acid (Fig. 2(c)) is a blue fluorescent material as well as an electronacceptor. From AFM and TEM studies, it has been reported that coronene molecules assist to exfoliate few-layer graphene as well as disperse single-layer and double-layer graphene [42]. The resulting graphenes could be used to build electronic devices.

(a)
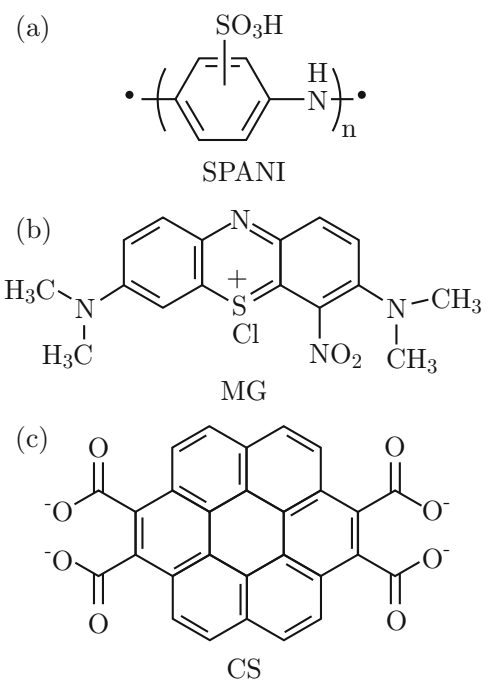

Fig. 2 The schematic structures of (a) sulfonated polyaniline; (b) methylene green and (c) tetrapotassium salt of coronene tetracarboxylic acid.

\section{Applications of graphene}

\section{Graphene based sensors}

Early research shows that graphene possesses excellent electronic and other interesting properties, suggesting that graphene is a promising material for sen- 
sors. The operational principle for graphene sensors is based on the change of electrical conductivity in graphene. When gas molecules are adsorbed onto the surface of graphene, charge transfer takes place between gas molecules and graphene [43]. It means that the adsorbed gas molecules are acting as charge donors or acceptors. This charge transfer results in the change in graphene's carrier concentration. Therefore, the electrical conductivity of graphene would be changed. Meanwhile, some interesting properties of graphene combine synergistically to increase its sensitivity up to single atom or molecular level detection. Firstly, graphene is a practical two-dimensional material with all atoms exposed to the environment [44]. Secondly, graphene is highly conductive (graphene's electrical conductivity is far better than that of copper), which means a little change in electrical properties would cause a notable signal. Thirdly, graphene has very few crystal defects, which could come up with noise by thermal minimum $[45,46]$. Finally, large-area ohmic contacts observed in graphene contribute to the reduction of resistance, resulting in making the measurements more convenient $[44,47]$.

Schedin et al. [44] first investigated graphene-based sensors in 2007. Since then, there have been a lot of reports on the sensing by graphene. According to Schedin's report [44], graphene demonstrates good sensing properties towards $\mathrm{NO}_{2}, \mathrm{NH}_{3}, \mathrm{H}_{2} \mathrm{O}$ and $\mathrm{CO}$. Going through vacuum annealing at $150^{\circ} \mathrm{C}$ or UV illumination for seconds, sensors based on graphene can be fully recovered. Utilizing enzymes and multi-layered graphene, Lu et al. [48] fabricated a sensitive glucose biosensor immobilized in Nafion. Attributing to the high sensitivity and selectivity, the authors suggested that the glucose biosensor based on multi-layered graphene could be an inexpensive alternative to carbon nanotubes for the fabrication of affordable high performance biosensors. By utilizing the four-point electrode system, Fowler et al. [47] suggest that electrode electrical contacts play a minimum role in the sensing mechanism of graphene. The sensing mechanism is primarily due to charge transfer between molecules and graphene. Sundaram et al. [49] chemically modified graphene surface by electrodeposition of $\mathrm{Pd}$ nanoparticles. This procedure may be advantageous, as the attached catalyst particles are expected to enhance sensitivity toward certain analytes, which cannot be directly detected by the unmodified material, due to insignificant response. The electro-deposition of $\mathrm{Pd}$ on graphene leads to the enhancement of the response of graphene sensors to $\mathrm{H}_{2}$ detection, as $\mathrm{Pd}$ has good affinity towards $\mathrm{H}_{2}$ detection.

With these key observations and results reported, graphene-based sensors have aroused great interests. However, there are several limitations for these devices. For example, it is absolutely mandatory to improve on the issue of selectivity. A sensor would be use- less if it responds in a similar way when exposed to any analyte. Fortunately, the selectivity issue can be overcome by the use of judicious chemistry to modify the graphene surface, which results in selective adsorption and provides specific binding sites. Such an approach would not only provide selective sensitivity to a large variety of chemical species; but also enable the detection of biological agents as well. Great improvements have been made in the selectivity issue for carbon nanotube based gas sensors. The experience from the carbon nanotube-based sensors could most likely accelerate the development of graphene-based gas sensors.

\section{Transparent conductive films}

Graphene exhibits exceptional electrical conductivity, high carrier mobility, and excellent optical transmittance, comparable with carbon nanotubes. Hence graphene holds potential for transparent conductive films (TCFs) application [50]. Graphene, the fascinating component of TCFs, can be fabricated by several methods: (1) GO-reduced graphene [51-57]; (2) graphene prepared by sonication of graphite in organic solvents, such as N-methyl-2-pyrrolidone and orthodichlorobenzene [58,59]; and (3) graphene grown on metal substrate by CVD [60-63]. The large scale productivity and low cost of GO-reduced graphene make it a superior candidate for the fabrication of TCFs. Due to the convenient processing of GO in water, usually GO was used as a precursor to be deposited onto the substrate, followed by chemically (or electrochemical) reduction or thermal annealing, and consequently formed graphene-based TCFs. Several processing of GO precursor, such as spin-coating [51,52], dip-coating [53], vacuum filtration [54], and LB assembly [55,57], have been carried out in order to form TCFs. The process of GO fabrication (oxidation) results in smaller sizes of graphite nanosheets, which affects the final resistance of the films. The resistance can be varied from $10^{3}$ to $10^{7} \Omega / \square$, due to the quality and connectivity of graphene. The TCFs prepared by sonication of graphite in N-methyl-2-pyrrolidone show a more stable resistance in the order of $10^{3} \Omega / \square$, because the quality of graphene has not been destroyed by sonication treatments. Transferring graphene grown on metal substrate by CVD can lead to much lower resistance of the resultant TCFs, due to the perfect quality and large sizes of graphene nanosheets. The resistance can be reached to the order of $10^{2} \Omega / \square$, and the values can be slightly varied, depending on the metal substrates used for the growth of graphene. However, the development of this method has been restricted by the preparation process. Since each method has its own advantages and drawbacks, we can judiciously exploit any method in accordance to the requirement. Actually, there is still a large amount of work that needs to 
be investigated for TCF applications, in order to reach the intrinsic resistance of graphene (about $30 \Omega / \square$ ) [60].

\section{Graphene/polymer nanocomposites}

Graphene plays a more and more important role in the polymer nanocomposite area, due to its comparable mechanical, thermal, and electrical properties with carbon nanotubes and also having much lower cost, making graphene suitable for industrial production and graphene offers a high potential for a variety of possible applications [3].

As for the preparation of graphene/polymer composites, dispersion of graphene polymer matrix is the most viable, since the properties of the composite materials are generally enhanced in a synergistic way. In order to prepare graphene/polymer nanocomposites, three main routes can be adopted: (1) solution blending method; (2) melt processing method; and (3) in situ polymerization method. Solution blending method is a very simple method for the preparation of polymer composites. The nanosheets, both of GO (with or without functionalization) and graphene, can be dispersed into the common solvents (polymer soluble), and mix with the polymer directly. Poly (vinyl acetate), as a common matrix, has been studied widely due to its water solubility [64-66]. Since GO can be dispersed in water easily, it can be incorporated into aqueous polymer dispersion at different concentrations. Further reduction (chemically or electrochemically) can then be carried out to obtain the graphene/polymer composites [67]. As for the general application of graphene in the nanocomposite fields, it's necessary to disperse the graphene sheets in most polymers, which are insoluble in water. Therefore, it is necessary to first disperse the graphene or GO nanosheets in an organic solvent, followed by polymer blending in the organic solvent. Therefore, the functionalization of graphene or GO sheets has been carried out in order to change the surface properties of nanosheets, making them more lipophilic and consequently dispersible in organic solvents $[24,68-75]$. Ruoff et al. [69,70] reported that GO can be chemically functionalized with isocyanate, and dispersed in organic solvents, followed by blending with polystyrene and a chemical reduction step. The results showed that graphene can be dispersed in polystyrene efficiently, and the obtained composite exhibited a high conductivity (Fig. 3). Wu et al. [68] reported that the graphene nanosheets can be grafted with long alkyl chains via simple amidation reaction. Compared with unmodified counterparts, the alkyl attached graphene shows a largely enhanced lipophilicity, and remarkably improvement of dispersion in the nonpolar solvents and polypropylene matrix can be achieved. Other kinds of polymer matrix composites with graphene-based additives, including poly (methyl methacrylate) [71,72], epoxy [73-76], polyester [77], silicone foam [78], polyurethane [79,80], poly (vinyldiene fluoride) [81], and polycarbonate [82] have also been reported. Melting processing method is another route for polymer processing, which is widely applied in industry area and very suitable for nanocomposite preparation through the addition of graphene-based additives into polymer matrix. Du et al. [83] reported the successful reduction of GO with polysulfide ions, leading to the formation of sulfur nanoparticles decorated graphene. Further melt blending of graphene with poly (arylene sulfide) resulted in highly exfoliated platelets in the polymer matrix. In situ polymerization is considered to be a very efficient method dispersing nanomaterials into the polymer matrix $[84,85]$. Through in situ polymerization, GO or graphene nanosheets have been successfully incorporated into many kinds of polymer matrix, such as poly (methyl methacrylate) [86,87], epoxy [88], and thermoplastic polyurethanes [80].
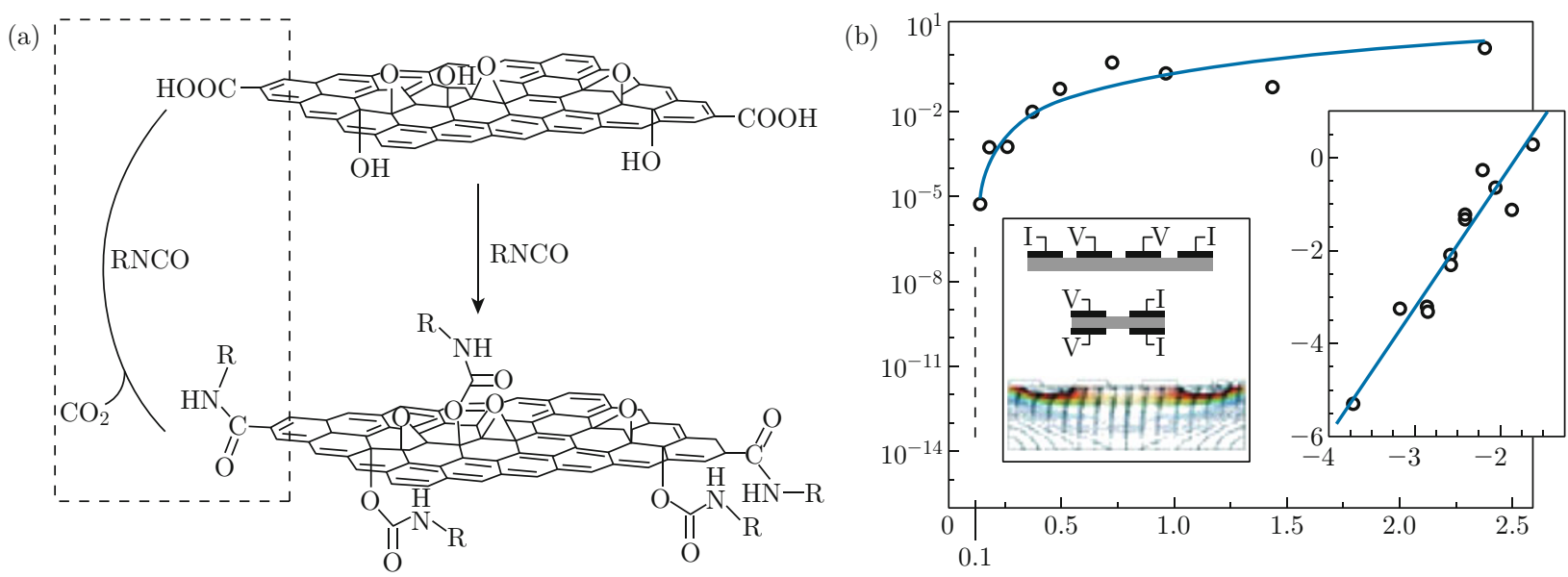

Fig. 3 The modification of GO (a) and the electrical conductivity of the polystyrene-graphene composites (b). The data are from Refs. 69 and 70. 
The mechanical, thermal, and electrical properties of polymer matrix can be significantly improved through the judicious addition of graphene-based additives. Moreover, compared with the conventional fillers, only a small amount of graphene is needed in order to achieve percolation $[72,89]$, due to the large interfacial area and high aspect ratio of graphene nanosheets. As a result, the properties of polymer matrix can be readily enhanced. Incorporating GO into poly (vinyl acetate) matrix, followed by a reduction process, result in a conductive composite with a percolation threshold below $1 \mathrm{wt} \%$ [66]. Poly (vinyl acetate) nanocomposites with loading as low as $0.7 \%$ showed $76 \%$ and $62 \%$ increase in tensile strength and Young's Modulus respectively [90]. The graphene/polymer nanocomposites with excellent thermal properties offer potential applications in electronic packaging and advanced composites. Addition of $25 \mathrm{vol} \%$ of graphene into epoxy can lead to the enhancement of the thermal conductivity by more than $3000 \%$ [76]. Therefore, graphene/epoxy nanocomposite can be considered as a useful candidate for thermal interface material application.

\section{Graphene resonators and radio frequency switches}

The unique properties of graphene have motivated intense work among physicists and engineers, discovering new opportunities to apply graphene in order to improve digital and radio frequency electronics [91], advanced sensors, transparent electronics, low-power switches, solar cells, as well as battery energy storage. In this article we review some of the recent progress made in the use of graphene devices for communication application.

Numerous communication systems rely on electromechanical devices, such as filters, resonators, and radio frequency switches. The miniaturization of these devices will strongly affect the development of future communication systems. The ultimate limit to this miniaturization is represented by graphene electromechanical devices, which are only one atom thick. In fact, its enormous stiffness and low density make graphene the ideal material for this kind of devices. The first electromechanical device ever demonstrated in graphene turns out to be nanomechanical resonators. In 2009 Chen et al. [92] fabricated monolayer graphene nanomechanical resonators with operating frequencies in the 50-80 $\mathrm{MHz}$ frequency range. These devices show quality factors in the order of $\sim 1 \times 10^{4}$ at low temperatures ( 5 $\mathrm{K})$. It has been predicted that the ability of graphene to withstand ultrahigh strains, up to $\sim 25$ percent in nanoindentation experiments, will allow the increase in the resonance frequency of these devices to above the gigahertz range, while maintaining a robust signal level. Graphene electromechanical switches have also been demonstrated recently. Milaninia et al. [93] developed a switch comprising of two polycrystalline graphene films grown by CVD. The top film is pulled into contact with the bottom one by applying a voltage of $5 \mathrm{~V}$ between the layers, and the contact is broken after removing the voltage due to restoring mechanical forces. In the ON state, more than $7 \mathrm{kA} / \mathrm{cm}^{2}$ of current can flow through the switch. Although the device performance suffers from a relatively large contact resistance, it is expected that the graphene-graphene contact will be more robust than the traditional metalmetal contact, leading to a significant increase in the reliability of future direct current and radio frequency switches.

\section{Conclusions}

In this review, we have discussed the methods related to the preparation, functionalization, and applications of graphene. In the course of the next ten years, it can be expected that there will be an explosion of reports on the new synthesis, functionalization, as well as applications of graphene. Along with the patents and publications, we will witness a revolution in nanoscience in which an entirely new industry and technology will emerge, based on graphene and the chemistry of functionalized graphene.

\section{Acknowledgments}

The project was supported by the National Natural Science Foundation of China (No. 50902092 and 51102164), Science and Technology Commission of Shanghai Municipality (No. 1052nm06800 and 1052nm02000), Shanghai Pujiang Program (No. 11PJD011), and the Program for Professor of Special Appointment (Eastern Scholar) at Shanghai Institutions of Higher Learning.

\section{References}

[1] X. Jia, J. Campos-Delgado, M. Terrones, V. Meunier and M. S. Dresselhaus, Nanoscale 3, 86 (2011). http://dx.doi.org/10.1039/c0nr00600a

[2] O. C. Compton and S. T. Nguyen, Small 6, 711 (2010). http://dx.doi.org/10.1002/smll.200901934

[3] B. Z. Jang and A. Zhamu, J. Mater. Sci. 43, 5092 (2008). http://dx.doi.org/10.1007/ s10853-008-2755-2

[4] W. Choi, I. Lahiri and R. Seelaboyina, Crit. Rev. Solid State Mater. Sci. 35, 52 (2010). http://dx.doi.org/ 10.1080/10408430903505036

[5] C. N. R. Rao, A. K. Sood, K. S. Subrahmanyam and A. Govindaraj, Angew. Chem. Int. Ed. 48, 7752 (2009). http://dx.doi.org/10.1002/anie. 200901678

[6] S. Park and R. S. Ruoff, Nat. Nanotechnol. 4, 217 (2009). http://dx.doi.org/10.1038/nnano.2009.58 
[7] J. Kim, F. Kim and J. Huang, Materialstoday 13, 28 (2010). http://dx.doi.org/10.1016/ S1369-7021(10)70031-6

[8] C. N. R. Rao, A. K. Sood, Rakesh Voggu and K. S. Subrahmanyam, J. Phys. Chem. Lett. 1, 572 (2010). http://dx.doi.org/10.1021/jz9004174

[9] A. K. Geim and K. S. Novoselov, Nat. Mater. 6, 183 (2007). http://dx.doi.org/10.1038/nmat1849

[10] X. Xie, L. Ju, X. Feng, Y. Sun, R Zhou, K. Liu, S. Fan, Q. Li and K. Jiang, Nano Lett. 9, 2565 (2009). http://dx.doi.org/10.1021/n1900677y

[11] P. Lauffer, K.V. Emtsev, R. Graupner, T. Seyller and L. Ley, Phys. Rev. B 77, 155426 (2008). http://dx . doi.org/10.1103/PhysRevB.77.155426

[12] X. Li, W. Cai, J. An, S. Kim, J. Nah, D. Yang, R. Piner, A. Velamakanni, I. Jung, E. Tutuc, S. K. Banerjee, L. Colombo and R. S. Ruoff, Science 324, 1312 (2009). http://dx.doi.org/10.1126/science. 1171245

[13] X. Li, W. Cai, L. Colombo and R. S. Ruoff, Nano Lett. 9, 4268 (2009). http://dx.doi.org/10.1021/ $\mathrm{n} 1902515 \mathrm{k}$

[14] V. C. Tung, M. J. Allen, Y. Yang and R. B. Kaner, Nat. Nanotechnol. 4, 25 (2009). http://dx.doi.org/ 10.1038/nnano. 2008.329

[15] G. I. Titelman, V. Gelman, S. Bron, R. L. Khalfin, Y. Cohen and H. BiancoPeled, Carbon 43, 64 (2005). http://dx.doi.org/10.1016/j.carbon.2004.10.035

[16] D. Cai and M. Song, J. Mater. Chem. 17, 3678 (2007). http://dx.doi.org/10.1039/b705906j

[17] J. I. Paredes, S. Rodil-Villar, A. Martínez-Alonso and J. M. D. Tascón, Langmuir 24, 10560 (2008). http:// dx.doi.org/10.1021/la801744a

[18] B. C. Brodie, Philos. Trans. R. Soc. London. 149, 249 (1859). http://dx.doi.org/10.1098/rstl.1859. 0013

[19] L. Staudenmaier, Ber. Dtsch. Chem. Ges. 31, 1481 (1898). http://dx.doi.org/10.1002/cber. 18980310237

[20] W. S. Hummers and R. E. Offeman, J. Am. Chem. Soc. 80, 1339 (1958). http://dx.doi.org/10.1021/ ja01539a017

[21] D. R. Dreyer, S. Park, C. W. Bielawski and R. S. Ruoff, Chem. Soc. Rev. 39, 228 (2010). http://dx.doi.org/ 10.1039/b917103g

[22] S. Gilje, S. Han, M.S. Wang, K. L. Wang and R. B. Kaner, Nano Lett. 7, 3394 (2007). http://dx.doi. org/10.1021/nl0717715

[23] Y. Y. Liang, D. Q. Wu, X. L. Feng, K. Müllen, Adv. Mater. 21, 1679 (2009). http://dx.doi.org/10.1002/ adma. 200803160

[24] J. F. Che, L. Y. Shen and Y. H. Xiao, J. Mater. Chem. 20, 1722 (2010). http://dx.doi.org/10.1039/ b922667b

[25] Z. J. Fan, K. Wang, T. Wei, J. Yan, L. P. Song and B. Shao, Carbon 48, 1670 (2010). http://dx.doi.org/ 10.1016/j.carbon. 2009.12.006

[26] J. L. Zhang, H. Y. Yang, G. X. Shen, P. Cheng, J. Y. Zhang and S. W. Guo, Chem. Commun. 46, 1112 (2010). http://dx.doi.org/10.1039/b917705a
[27] Y. Chen, X. Zhang, P. Yu and Y. W. Ma, Chem. Commun. 4527 (2009). http://dx.doi.org/10.1039/ b907723e

[28] G. Williams, B. Seger and P.V. Kamat, ACS Nano 2, 1487 (2008). http://dx.doi.org/10.1021/nn800251f

[29] H. L. Guo, X. F. Wang, Q. Y. Qian, F. B. Wang and X. H. Xia, ACS Nano 3, 2653 (2009). http://dx.doi. org/10.1021/nn900227d

[30] Z. Li, Y. G. Yao, Z. Y. Lin, K. S. Moon, W. Lin and C. P. Wong, J. Mater. Chem. 20, 4781 (2010). http:// dx.doi.org/10.1039/c0jm00168f

[31] K. P. Loh, Q. Bao, P. K. Ang and J. Yang, J. Mater. Chem. 20, 2277 (2010). http://dx.doi.org/10.1039/ b920539j

[32] X. Wu and P. Liu, Macromol. Res. 18, 101008 (2010). http://dx.doi.org/10.1007/s13233-010-1014-y

[33] M. Quintana, K. Spyrou, M. Grzelczak, W. R. Browne, P. Rudolf and M. Prato, ACS Nano 4, 3527 (2010). http://dx.doi.org/10.1021/nn100883p

[34] J. R. Lomeda, C. D. Doyle, D. V. Kosynkin, W. F. Hwang and J. M. Tour, J. Am. Chem. Soc. 130, 16201 (2008). http://dx.doi.org/10.1021/ja806499w

[35] Y. Xu, Z. Liu, X. Zhang, Y. Wang, J. Tian, Y. Huang, Y. Ma, X. Y. Zhang and Y. Chen, Adv. Mater. 21, 1275 (2009). http://dx.doi.org/10.1002/adma. 200801617

[36] J. F. Shen, N. Li, M. Shi, Y. Z. Hu and M. X. Ye, J. Colloid Interface Sci. 348, 377 (2010). http://dx.doi. org/10.1016/j.jcis.2010.04.055

[37] S. Alwarappan, C. Liu, A. Kumar and C. Li, J. Phys. Chem. C 114, 12920 (2010). http://dx.doi.org/10. 1021/jp103273z

[38] Q. Yang, X. Pan, F. Huang and K. Li, J. Phys. Chem. C 114, 3811 (2010). http://dx.doi.org/10. 1021/jp910232x

[39] H. Bai, Y. Xu, L. Zhao, C. Li and G. Shi, Chem. Commun. 13, 1667 (2009). http://dx.doi.org/10.1039/ b821805f

[40] E. Choi, T. H. Han, J. Hong, J. Kim, S. H. Lee, H. W. Kim and S. O. Kim, J. Mater. Chem. 20, 1907 (2010). http://dx.doi.org/10.1039/b919074k

[41] H. Liu, J. Gao, M. Xue, N. Zhu, M. Zhang and T. Cao, Langmuir 25, 12006 (2009). http://dx.doi.org/10. 1021/la9029613

[42] A. Ghosh, K. V. Rao, S. J. George and C. N. R. Rao, Chem. Eur. J. 16, 2700 (2010). http://dx.doi.org/ 10. $1002 /$ chem. 200902828

[43] G. Ko, H. Y. Kim, J. Ahn, Y. M. Park, K. Y. Lee and J. Kim, Curr. Appl. Phys. 10, 1002 (2010). http:// dx.doi.org/10.1016/j.cap. 2009.12.024

[44] F. Schedin, A. K. Geim, S. V. Morozov, E. W. Hill, P. Blake, M. I. Katsnelson and K. S. Novoselov, Nat. Mater. 6, 652 (2007). http://dx.doi.org/10.1038/ nmat 1967

[45] K. S. Novoselov, A. K. Geim, S. V. Morozov, D. Jiang, M. I. Katsnelson, I. V. Grigorieva, S. V. Dubonos and A. A. Firsov, Nature 438, 197 (2005). http://dx.doi. org/10.1038/nature04233 
[46] K. S. Novoselov, Z. Jiang,Y. Zhang, S. V. Morozov, H. L. Stormer, U. Zeitler, J. C. Maan, G. S. Boebinger, P. Kim and A. K. Geim, Science 315, 1379 (2007). http://dx.doi.org/10.1126/science.1137201

[47] J. D. Fowler, M. J. Allen, V. C. Tung, Y. Yang, R. B. Kaner and B. H. Weiller, ACS Nano 3, 201 (2009). http://dx.doi.org/10.1021/nn800593m

[48] J. Lu, L. T. Drzal, R. M.Worden and I. Lee, Chem. Mater. 19, 6240 (2007). http://dx.doi.org/10.1021/ cm702133u

[49] R. S. Sundaram, C. G. Navarro, K. Balasubramaniam, M. Burghard and K. Kern, Adv. Mater. 20, 3050 (2008). http://dx.doi.org/10.1002/adma. 200800198

[50] Y. Zhu, S. Murali, W. Cai, X. Li, J. Suk, J. R. Potts and R. S. Ruoff, Adv. Mater. 22, 3906 (2010). http:// dx.doi.org/10.1002/adma. 201001068

[51] S. Watcharotone, D. A. Dikin, S. Stankovich, R. Piner, I. Jung, G. H. B. Dommett, G. Evmenenko, S. E. Wu, S. F. Chen, C. P. Liu, S. T. Nguyen and R. S. Ruoff, Nano Lett. 7, 1888 (2007). http://dx.doi.org/10. $1021 / \mathrm{nl} 070477+$

[52] H. A. Becerril, J. Mao, Z. Liu, R. M. Stoltenberg, Z. Bao and Y. Chen, ACS Nano 2, 463 (2008). http:// dx.doi.org/10.1021/nn700375n

[53] X. Wang, L. J. Zhi and K. Mullen, Nano Lett. 8, 323 (2008). http://dx.doi.org/10.1021/n1072838r

[54] G. Eda, G. Fanchini and M. Chhowalla, Nat. Nanotechnol. 3, 270 (2008). http://dx.doi.org/10.1038/ nnano. 2008.83

[55] L. J. Cote, F. Kim and J. X. Huang, J. Am. Chem. Soc. 131, 1043 (2009). http://dx.doi.org/10.1021/ ja806262m

[56] D. Li, M. B. Muller, S. Gilje, R. B. Kaner and G. G. Wallace, Nat. Nanotechnol. 3, 101 (2008). http://dx. doi.org/10.1038/nnano.2007.451

[57] Y. Zhu, W. Cai, R. D. Piner, A. Velamakanni and R. S. Ruoff, Appl. Phys. Lett. 95, 103104 (2009). http:// dx.doi.org/10.1063/1.3212862

[58] S. De, P. J. King, M. Lotya, A. O'Neill, E. M. Doherty, Y. Hernandez, G. S. Duesberg and J. N. Coleman, Small 6, 458 (2009). http://dx.doi.org/10. 1002/smll. 200901162

[59] C. E. Hamilton, J. R. Lomeda, Z. Sun, J. M. Tour and A. R. Barron, Nano Lett. 9, 3460 (2009). http://dx . doi.org/10.1021/nl9016623

[60] D. Wei, Y. Liu, Y. Wang, H. Zhang, L. Huang and G. Yu, Nano Lett. 9, 1752 (2009). http://dx.doi.org/ 10.1021/nl803279t

[61] X. Li, Y. Zhu, W. Cai, M. Borysiak, B. Han, D. Chen, R. D. Piner, L. Colombo and R. S. Ruoff, Nano Lett. 9, 4359 (2009). http://dx.doi.org/10.1021/n1902623y

[62] A. Reina, X. T. Jia, J. Ho, D. Nezich, H. B. Son, V. Bulovic, M. S. Dresselhaus and J. Kong, Nano Lett. 9, 3087 (2009). http://dx.doi.org/10.1021/n1901829a

[63] J. H. Chen, C. Jang, S. D. Xiao, M. Ishigami and M. S. Fuhrer, Nat. Nanotechnol. 3, 206 (2008). http:// dx.doi.org/10.1038/nnano.2008.58

[64] Y. Matsuo, K. Tahara and Y. Sugie, Chem. Mater. 9, 1 (1998).
[65] J. Y. Xu, Y. Hu and L. Song, Polym. Degrad. Stab. 73, 29 (2001). http://dx.doi.org/10.1016/ S0141-3910 (01) 00046-5

[66] J. Xu, Y. Hu, L. Song, Q. Wang, W. Fan and Z. Chen, Carbon 40, 450 (2002). http://dx.doi.org/10.1016/ S0008-6223(01) 00134-8

[67] H. J. Salavagione, G. Martinez and M. A. Gomez, J. Mater. Chem. 19, 5027 (2009). http://dx.doi.org/ 10.1039/b904232f

[68] Y. Cao, J. Feng and P. Wu, Carbon 48, 1683 (2010). http://dx.doi.org/10.1016/j.carbon.2009.12.061

[69] S. Stankovich, D. Dikin, G. H. B. Dommett1, K. M. Kohlhaas, E. J. Zimney, E. A. Stach, R. D. Piner, S. T. Nguyen and R. S. Ruoff, Nature 442, 282 (2006). http://dx.doi.org/10.1038/nature04969

[70] S. Stankovich, R. D. Piner, S. T. Nguyen and R. S. Ruoff, Carbon, 44, 3342 (2006). http://dx.doi.org/ $10.1016 / j$. carbon. 2006.06.004

[71] S. H. Lee, D. R. Dreyer, J. A. A. Velamakanni, R. D. Piner, S. Park, Y. Zhu, S. O. Kim, C. W. Bielawski and R. S. Ruoff, Macromol. Rapid Commun. 31, 281 (2010). http://dx.doi.org/10.1002/ marc. 200900641

[72] T. Ramanathan, A. A. Abdala, S. Stankovich, D. A. Dikin, M. Herrera-Alonso, R. D. Piner, D. H. Adamson, H. C. Schniepp, X. Chen, R. S. Ruoff, S. T. Nguyen, I. A. Aksay, R. K. Prud'homme and L. C. Brinson, Nat. Nanotechnol. 3, 327 (2008). http://dx. doi.org/10.1038/nnano.2008.96

[73] S. Ganguli, A. K. Roy and D. P. Anderson, Carbon 46, 806 (2008). http://dx.doi.org/10.1016/j.carbon. 2008.02 .008

[74] M. A. Rafiee, J. Rafiee, Z. Z. Yu and N. Koratkar, Appl. Phys. Lett. 95, 3 (2009). http://dx.doi.org/ 10.1063/1.3269637

[75] S. R. Wang, M. Tambraparni, J. J. Qiu, J. Tipton and D. Dean, Macromolecules 42, 5251 (2009). http://dx. doi.org/10.1021/ma900631c

[76] A. P. Yu, P. Ramesh, M. E. Itkis, E. Bekyarova and R. C. Haddon, J. Phys. Chem. C 111, 7565 (2007). http://dx.doi.org/10.1021/jp071761s

[77] H. Kim and C. W. Macosko, Macromolecules 41, 3317 (2008). http://dx.doi.org/10.1021/ma702385h

[78] R. Verdejo, F. Barroso-Bujans, M. A. RodriguezPerez, J. A. de Saja and M. A. Lopez-Manchado, J. Mater. Chem. 18, 2221 (2008). http://dx.doi.org/ 10.1039/b718289a

[79] D. Cai, K. Yusoh and M. Song, Nanotechnology 20, 085712 (2009). http://dx.doi.org/10.1088/ 0957-4484/20/8/085712

[80] Y. R. Lee, A. V. Raghu, H. M. Jeong and B. K. Kim, Macromol. Chem. Phys. 210, 1247 (2009). http://dx. doi.org/10.1002/macp. 200900157

[81] S. Ansari and E. P. Giannelis, J. Polym. Sci., Part B: Polym. Phys. 47, 888 (2009). http://dx.doi.org/10. 1002/polb. 21695

[82] H. Kim and C. W. Macosko, Polymer 50, 3797 (2009). http://dx.doi.org/10.1016/j.polymer. 2009.05. 038 
[83] X. S. Du, Z. Z. Yu, A. Dasari, J. Ma, M. S. Mo, Y. Z. Meng and Y. W. Mai, Chem. Mater. 20, 2066 (2008). http://dx.doi.org/10.1021/cm703285s

[84] Y. Du, N. T. Hu, H. W. Zhou, P. Li, P. Zhang, X. G. Zhao, G. D. Dang and C. H. Chen, Polym. Int. 58, 832 (2009). http://dx.doi.org/10.1002/pi.2602

[85] N. T. Hu, H. W. Zhou, G. D. Dang, X. H. Rao, C. H. Chen and W. J. Zhang, Polym. Int. 56, 655 (2007). http://dx.doi.org/10.1002/pi.2187

[86] J. Y. Jang, M. S. Kim, H. M. Jeong and C. M. Shin, Compos. Sci. Technol. 69, 186 (2009). http://dx.doi. org/10.1016/j.compscitech. 2008.09.039

[87] W. P. Wang and C. Y. Pan, Polym. Eng. Sci. 44, 2335 (2004). http://dx.doi.org/10.1002/pen. 20261

[88] J. Liang, Y. Wang, Y. Huang, Y. Ma, Z. Liu, J. Cai, C. Zhang, H. Gao and Y. Chen, Carbon 47, 922 (2009). http://dx.doi.org/10.1016/j.carbon.2008.12.038
[89] P. Steurer, R. Wissert, R. Thomann and R. Mulhaupt, Macromol. Rapid Commun. 30, 316 (2009). http:// dx.doi.org/10.1002/marc . 200800754

[90] J. J. Liang, Y. Huang, L. Zhang, Y. Wang, Y. F. Ma, T. Y. Guo and Y. S. Chen, Adv. Funct. Mater. 19, 2297 (2009).http://dx.doi.org/10.1002/adfm. 200801776

[91] T. Palacios, A. Hsu and H. Wang, IEEE Commun. Mag. 48, 122 (2010). http://dx.doi.org/10.1109/ MCOM. 2010. 5473873

[92] C. Chen, S. Rosenblatt, K. I. Bolotin, W. Kalb, P. Kim, I. Kymissis, H. L. Stormer, T. F. Heinz and J. Hone, Nat. Nanotech. 4, 861 (2009). http://dx.doi. org/10.1038/nnano. 2009. 267

[93] K. M. Milaninia, M. A. Baldo, A. Reina and J. Kong, Appl. Phys. Lett. 95, 183105 (2009). http://dx.doi. org/10.1063/1.3259415 